\title{
Implementing a Short Regimen for Multidrug-Resistant Tuberculosis in Kinshasa, Democratic Republic of Congo: A Cohort Study 2014-2017
}

\section{Innocent Murhula Kashongwe ${ }^{1,2,3 *}$, Leopoldine Mbulula ${ }^{2}$, Fina Mawete ${ }^{3}$, Nicole Anshambi ${ }^{4}$, Nadine Maingowa ${ }^{4}$, Michel Kaswa ${ }^{3}$, Jean Marie Ntumba Kayembe', Francois Bompeka Lepira ${ }^{1}$, Zacharie Munogolo Kashongwe ${ }^{1}$}

\author{
${ }^{1}$ Pulmonology Unit, Internal Medicine, Kinshasa University Hospital, Kinshasa, Democratic Republic of the Congo \\ ${ }^{2}$ Drug Resistant Tuberculosis Unit “Centre Excellence Damien”, Damian Foundation, Kinshasa, \\ Democratic Republic of the Congo \\ ${ }^{3}$ National Tuberculosis Program of the Democratic Republic of the Congo, Kinshasa, Democratic Republic of the Congo \\ ${ }^{4}$ Provincial Coordination for Tuberculosis Control, Kinshasa, Democratic Republic of the Congo \\ Email: ${ }^{\star}$ innocent.kashongwe@unikin.ac.cd
}

How to cite this paper: Kashongwe, I.M., Mbulula, L., Mawete, F., Anshambi, N., Maingowa, N., Kaswa, M., Kayembe, J.M.N., Lepira, F.B. and Kashongwe, Z.M. (2020) Implementing a Short Regimen for Multidrug-Resistant Tuberculosis in Kinshasa, Democratic Republic of Congo: A Cohort Study 2014-2017. Journal of Tuberculosis Research, 8, 111-126. https://doi.org/10.4236/jtr.2020.83010

Received: May 27, 2020

Accepted: July 14, 2020

Published: July 17, 2020

Copyright $\odot 2020$ by author(s) and Scientific Research Publishing Inc. This work is licensed under the Creative Commons Attribution International License (CC BY 4.0).

http://creativecommons.org/licenses/by/4.0/ (c) (i) Open Access

\begin{abstract}
Setting. Kinshasa, capital of Democratic Republic of Congo, has the high rate of multidrug resistant tuberculosis (MDR-TB) which is associated with poor treatment outcomes until 2013. A new approach was needed. Objectives. To implement a new strategy in order to improve treatment outcomes. Design: A retrospective cohort study reviewing all the patients diagnosed MDR Tuberculosis between 2014 and 2017. The study was conducted in the National Tuberculosis Program (NTP) framework comparing the short regimen and the WHO standard regimen. Results. From 1246 patients diagnosed RR/TB, 1073 were included in the analysis: 948 on shorter regimen, and 125 on WHO standard regimen. The strategy was based on patient-centered care. In the short regimen group, $62.7 \%$ were male, $61.4 \%$ were age 25 - 44 years, $52.6 \%$ had previous history of TB, 39.3\% underweight, $12.5 \%$ HIV positive. The median time from diagnosis to treatment was 19 days $(0-163)$. In the long regimen group, $75 \%$ were male, $37.6 \%$ were age 14 - 44 years, $61.6 \%$ underweight, $18.4 \%$ HIV positive. The median time from diagnosis to treatment was 19 days (0 - 114). Favorable outcomes represented $81.9 \%$ in the short regimen group versus $72 \%$ in the long regimen group. Death and loss to follow-up were more observed in long regimen group (27.2\% versus $15.4 \%)$. Factors associated with unfavorable outcomes in the short regimen group included sex, age $\geq 45$ years, previous TB history, HIV status, delay to begin treatment. For the long
\end{abstract}


regimen, the factors age and delay emerged, underweight and HIV were borderline. Drug adverse events were reported respectively in $43.5 \%$ and $42.4 \%$ for short and long regimen; with gastrointestinal disturbances, vestibular troubles, ototoxicity, arthralgia and anemia as the most common in the 2 groups. Conclusion: The new approach improved favorable outcomes. Both short and long regimens reached a high level of favorable outcome compared to the previous study. The short regimen, well supervised seems to be superior to the long regimen in term of Death rate and loss to follow up (LTFU).

\section{Keywords}

MDR-TB, Short Regimen, Patient, Centered Card

\section{Introduction}

Despite overall progress in global Tuberculosis (TB) control from 1998, the emerging of multidrug-resistant tuberculosis (MDR/TB), defined as where the Mycobacterium Tuberculosis is resistant to at least isoniazid and rifampicin [1] [2], represents a threat for the end of the worldwide epidemic by 2030 [3] [4] [5] [6]. All countries are concerned [1] [7] [8] [9] [10] [11]. Among the 30 countries heavily affected, we can find: India, China, Russian Federation, Philippines, Pakistan, Brazil, South Africa and Democratic Republic of Congo (DR Congo) [1]. Another category in which additional resistant to second line injectable drugs (SLID), e.g. amikacin, capreomycin, kanamycin and quinolone is called extensively drug-resistant TB (XDR-TB) [1]. Treatment of MDR-TB is expensive; drugs are difficult to obtain, and have many adverse events. Favorable outcomes remain poor [6] [10] [12]-[20].

In DR Congo, National Tuberculosis Program (NTP) applies WHO guidelines from 2006 for MDR/TB management. A cohort study conducted in Kinshasa, from 2009 to 2012, revealed a poor therapeutic success (cured + treatment completed) about $36 \%$ (20), meanwhile this was reported to be about $48 \%$ and $54 \%$ by other studies [1] [6] [21] [22]. The low performance can be attributed to many factors: delay in diagnosis and treatment, lack of treatment adherence, drugs adverse events, long duration of treatment, overloaded health services [1] [6] [22]. Some good results have been reported in Cameroon [23], Niger [24], and Bangladesh [25] [26] with shorter regimens of 9 - 12 months. Trébucq A. et al. qualified this as "a decade of evidence" [27]. That is why we decided to reform drug resistant TB management in Kinshasa and to introduce the short regimen for eligible patients from 2014 [4] [27]. Kinshasa, DR Congo capital, contributes to $35 \%$ of the all country $\mathrm{MDB} / \mathrm{TB}(28)$.

\section{Methods}

\section{Study population:}

This is a retrospective cohort study. It analyses all patients diagnosed with rifampicin resistance (RR) by genotypic method (Xpert ${ }^{\oplus}$ MTB/RIF, Cepleid, USA) 
in different health centers for the period 2014-2017. Samples from the health centers have been subjected to the Line Probe Assay (LPA-MDR DR plus-sl or Hain-test) to test other drugs (Isoniazid, Fluoroquinolone, Second Line injectable drugs) and thus exclude XDR-TB. All samples have been also sent for performing Lowenstein-Jensen (LJ) culture. It was not possible to do drug sensitivity test (DST) for all the anti-tuberculosis drugs. We excluded for analysis: patients without LPA or culture results, with severe hearing loss, rifampicine sensitive on LPA or culture, SLID and fluoroquinolone resistant (Figure 1). Eligible patients received short or long regimen according to the established criteria.

\section{Short regimen criteria:}

Includable patients had to commit themselves not to change residential address for the duration of treatment and to sign a consent form. Patient known to have previously been treated with second line drugs, to have resistance to fluoroquinolone (FQ) or any second-line injectable drug (SLID), pregnant women, patients with known intolerance to a study drug, or with a pretreatment electrocardiogram (ECG) showing QT interval > $500 \mathrm{~ms}$, were not eligible. In this study, patients under 18 years old were included.

\section{Long regimen criteria:}

All the patients excluded from the short regimen received long regimen according NTP and WHO guidelines [12] or individualized regimen. The patients who received individualized regimen were excluded for analysis.

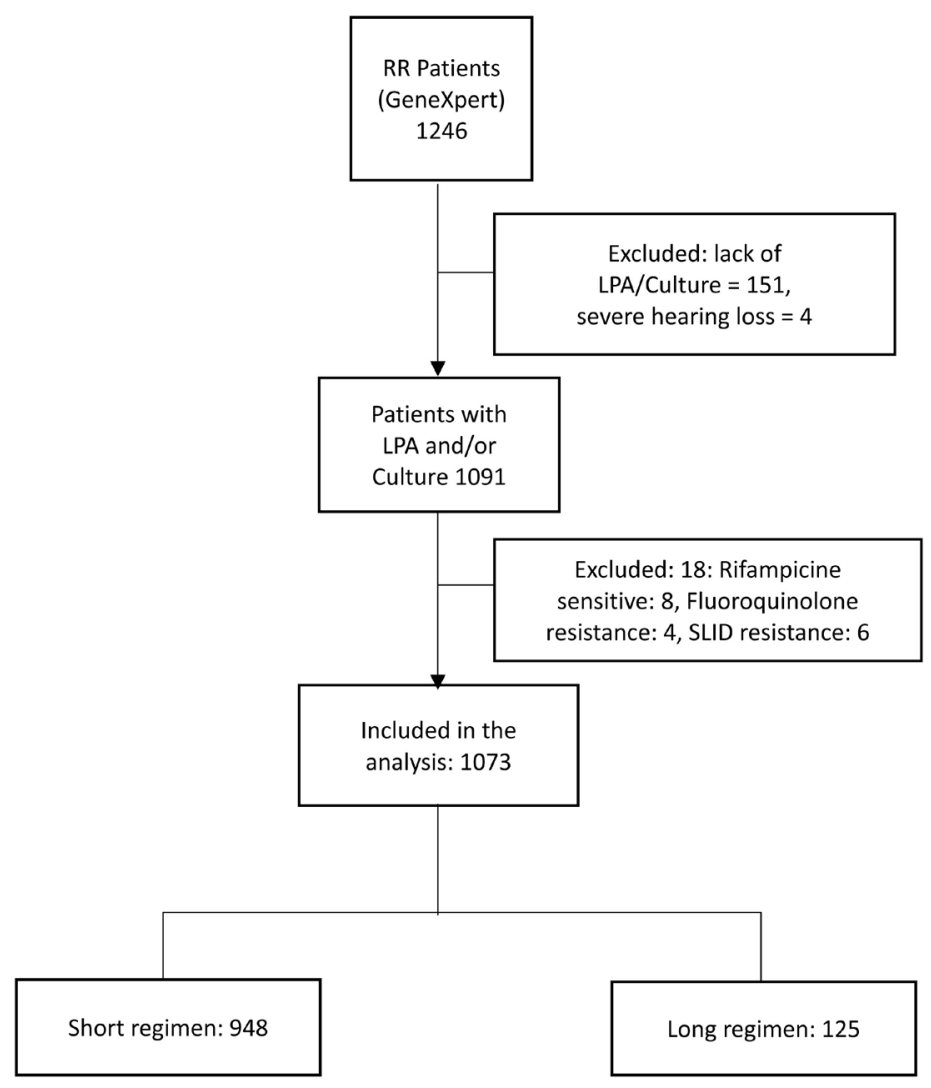

Figure 1. Flow chart of patients enrollment. 


\section{Treatment regimens:}

For the short regimen, we used the one selected for the 9 African French speaking countries study [22]. The intensive phase consisted of moxifloxacin (MFX), Ethambutol (EMB), high-dose isoniazid (INHh), pyrazimanide (PZA) and Prothionamide (PTO) given daily for 4 months. If the sputum smear examination was still positive at 4 months, the intensive phase was extended by a maximum of 2 months. The continuation phase consisted of normal dose MFX, EMB, PZA and CFZ given daily for a fixed 5-monthsperiod. Drug dosages are those recommended by WHO [12]. So regimen can be summarized as: 4 - 6 (Km, CFZ, MFX, EMB, INHh, PZA, PTO) + 5 (MFX, EMB, PZA, CFZ). For the long regimen, we use the standard WHO 20 months one [12].

\section{Patients management.}

Treatment was daily and directly observed by a nurse and a community health worker throughout the entire duration. Ambulatory treatment was given from the onset expect emergencies. Specifically prepared cards facilitated recording of patient characteristics, clinical controls, test results, adverse events and follow-up of drug intake.

Adverse events, including biological abnormalities detected, were recorded monthly and graded using the ANRS (Agence Nationale de Recherchesur le SIDA) score [29], which includes 4 grades ranking from grade 1 (mild) to grade 4 (severe, life-threatening). Bacteriological follow-up (sputum smear, culture) was monthly realized until $9^{\text {th }}$ month, then at $12,15,20$ months for the long regimen and 6 months after the treatment completion for all the patients [30]. Other tests realized at the beginning and according a planning during treatment were: hemoglobin, white cells count, serum creatinine, lives enzymes (aminotransferases), potassium, HIV test, ECG, pregnancy test for young women, audiometry (to screen hearing loss) [22]. QT interval was corrected by Fridericia formula [12]. Hearing loss was checked as previously described [22].

\section{Definitions.}

For outcomes, we used the WHO treatment outcomes definitions except for "cured" and "treatment failure" because of the short treatment duration [22] [31].

- Cured: treatment completed without evidence of failure and three or more consecutive negative cultures taken at least 30 days apart;

- Treatment failed: treatment terminated due to a positive culture after 6 months of treatment (except when preceded by 1 negative and followed by at least 2 negatives cultures and not ever anymore a positive, i.e. "isolated positive culture".

For patients under long regimen, the definitions remained unchanged [12]. Radiography extent of lesions has been classified according the area concerned [32]. For body mass index, 3 groups were defined: under $18.5=$ underweight, 18.5 - 24.9: normal, 25 and over = over weight.

\section{Implementing strategy:}

Problems identified by the cohort study 2009-2012 conducted in Kinshasa 
highlighted the weakness of the system and imposed to change approach by intensifying patient-centered care [33] [34] [35] [36] [37]. The main steps were:

- To select 35 health centers among 144 present in Kinshasa and specialize them in drug resistant TB management, by training nurses and community health workers;

- To give them supply and second line drugs,

- To select a central laboratory for DR/TB follow-up tests,

- To train a staff with a clinical monitor for monthly visits in the health centers selected,

- To procure nutritional assistance and transport money for the control visits,

- To build a specialized center, able to manage DR/TB emergencies and hospitalization: The Damian Excellency Center (Centre d'Excellence Damien or CEDA).

\section{Data managementand analysis.}

Data were captured in Excel 2010. Analysis was performed using STATA, version 13 (Statacorp, college station, TX, USA). Difference in time to culture and smear conversion was analyzed using Cox proportional hazards method. We used univariate and multivariate statistics, determining point estimates, 95\% confidence interval $(95 \% \mathrm{CI})$, odd ratio (OR), adjusted add ratio (aoR), p values where appropriate.

Ethics considerations.

The study protocol was approved by the ethics committee of the Public Health School of Kinshasa. The study was organized within the framework of the NTP and treatment was provided free of charge. Patients had to sign consent form. Data were collected anonymously. Failure cases received an individualized treatment according to the DST.

\section{Results}

During the study period, 1246 patients RR/TB were identified by genotypic method (Xpert ${ }^{\oplus}$ MTB/Rif); 174 (13.9\%) were excluded for analysis. From the 1073 remaining, 125 underwent WHO standard regimen and 948 the $9-11$ months short regimen.

\section{Patients baseline characteristics.}

The baseline characteristics are shown in Table 1. Most of patients were male and aged $25-44$ years in the 2 groups. Over $50 \%$ had a previous Tuberculosis history. Nearly two thirds were underweight with a BMI $<18.5 \mathrm{~kg} / \mathrm{m}^{2}$ in the long regimen group while this was observed only in $39 \%$ in the short regimen group $(\mathrm{p}<0.01)$. About $18.4 \%$ and $12.5 \%$ were HIV positive respectively in long and short regimen group. $(\mathrm{p}<0.01)$.

\section{Time to treatment initiation:}

The median time from diagnosis to start of MDR-TB treatment was the same in the two groups (19 days (range 0 - 163) in the short versus 19 (range 0 - 114) in the long regimen group). But $19.2 \%$ of patients in the short regimen group vs $7.2 \%$ in the long experienced a long delay before starting treatment. This was 
Table 1. Patients baseline characteristics.

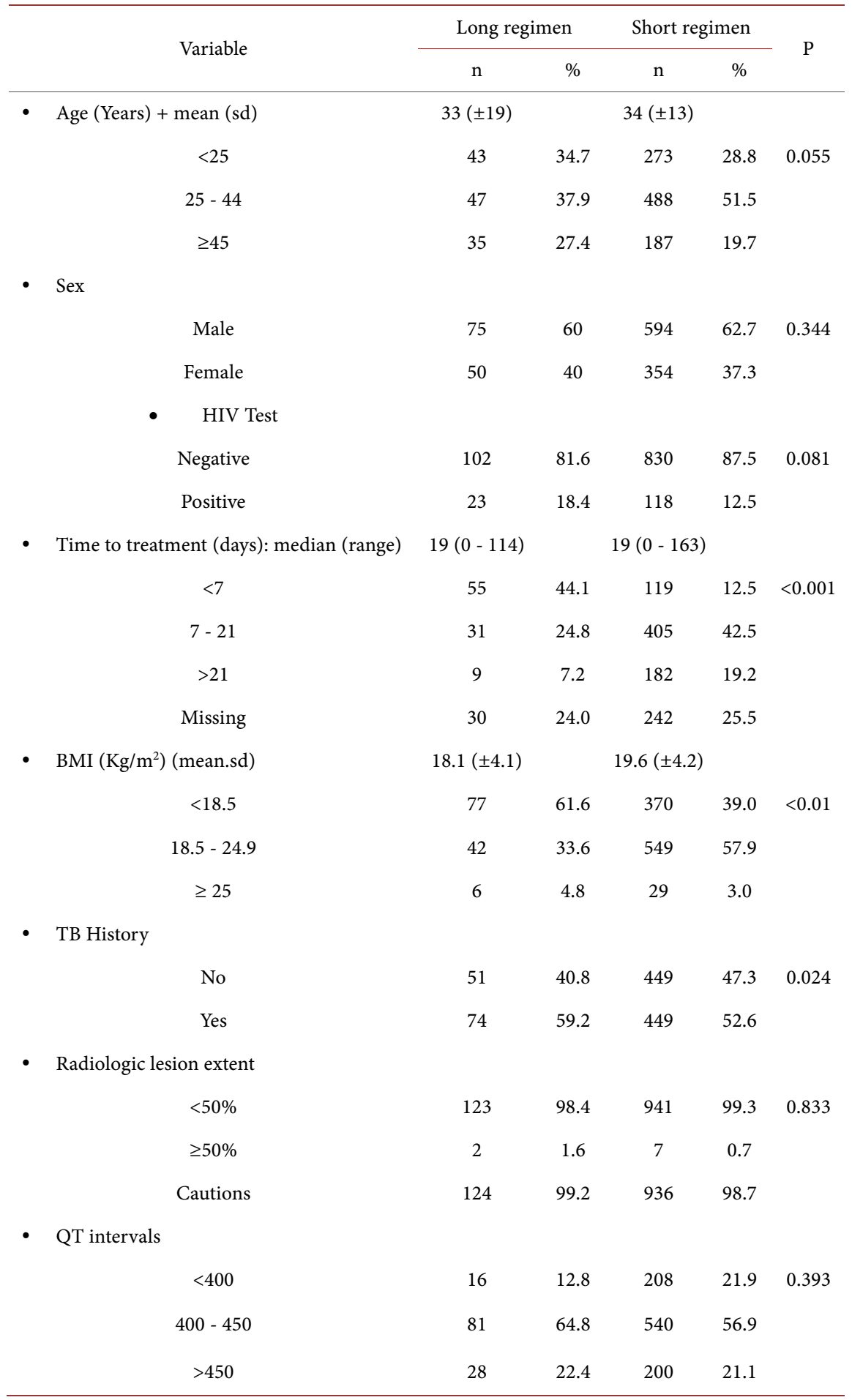

mainly due to logistic problems as drugs were not supported in the PNLT. Details are shown in Table 1.

Bacteriological follow-up:

Smear and culture controls presented similar profile (Figure 2 and Figure 3). At 2, 4, 6 month's controls, negative smear results were respectively $85.0 \%$, 


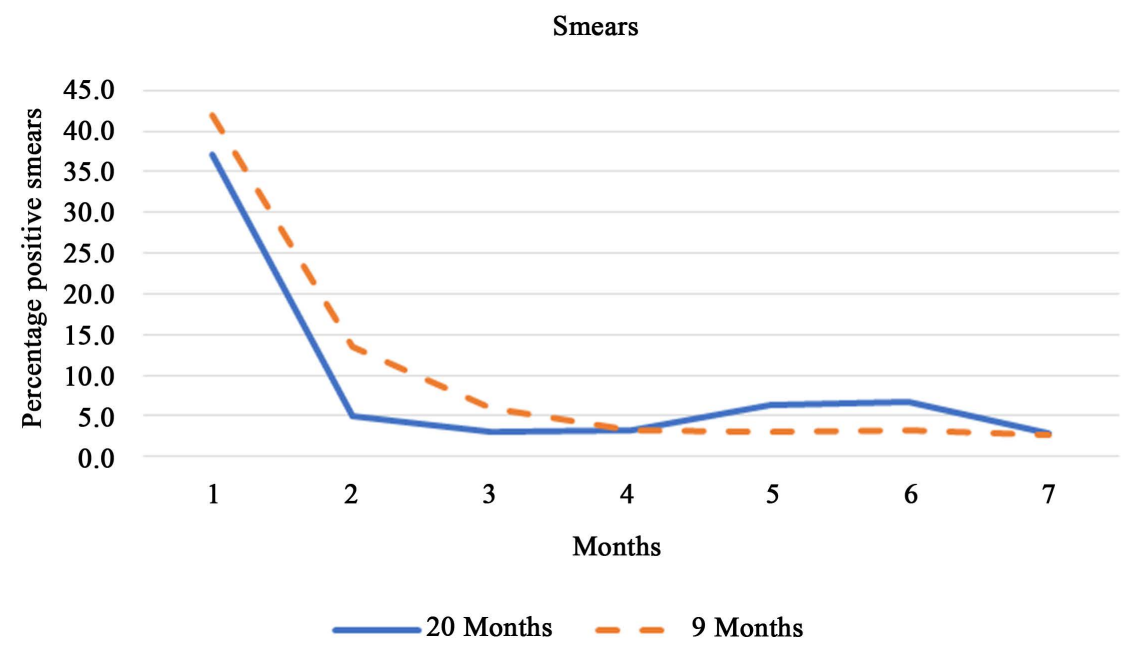

Figure 2. Smear conversion: The two groups presented the same profile.

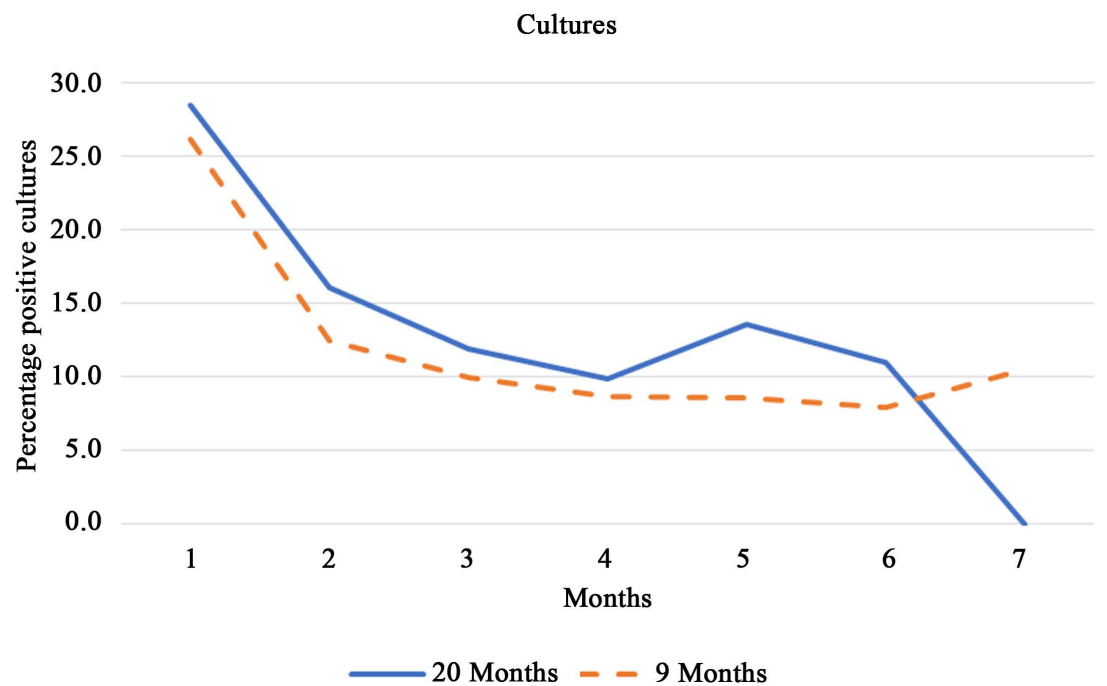

Figure 3. Cultures conversion: the same profile is also seen unless a small variation between the $4^{\text {Th }}$ and $6^{\text {th }}$ month.

93.1\%, $96.7 \%$ in the long regimen group and $86.4 \%, 96.6 \%, 96.7 \%$ in the short regimen group for patients who achieved follow up. About cultures, negative results at the same periods were respectively $83.6 \%, 88.9 \%$ and $90.1 \%$ in the long and $87.5 \%, 91.1 \%$, and $92.0 \%$ in the short regimen group. Three patients in the long regimen group and 2 in the short regimen had intensive phase extended because a positive control was identified at the end of the intensive phase. One patient in the short regimen group presented a reversion by 7 month's control; DST revealed resistance to fluoroquinolone and individualized regimen was prescribed.

\section{Other control tests:}

Disturbance in liver enzymes (aminotransferases) were reported in one case of toxic hepatitis, it resolved during treatment. Other tests (serum creatinine, Kalemia) remained in the normal ranges. Some anemia cases were diagnosed and 
treated. QTc interval variations remained under $500 \mathrm{~ms}$ in the 2 groups. Before treatment, mean QTc interval was respectively 423 (range 332 - 495) ms and 425 (range 367 - 475) ms in short and long regimen group. The 4 months control registered 422 (range 328 - 480) and 423 (range 398 - 475) in the short and long regimen group.

\section{Treatment outcomes:}

Overall treatment success was $72.0 \%$ in long regimen versus $81.9 \%$ in short regimen. Of the $28 \%$ of patients with unfavorable treatment outcomes in the long regimen group, most were due to death (14.4\%) or LTFU (12.8\%). Mean while from the $18.1 \%$ of unfavorable outcomes in short regimen, only $9.2 \%$ were due to death. In bivariate analysis, factors associated with unfavorable outcomes in short regimen group were: male sex $(\mathrm{p}=0.05)$, HIV status $(\mathrm{p}=0.001)$, TB history (0.05), delay of treatment over 30 days (0.001) and radiologic lesions extent with cavities $(\mathrm{p}=0.05)$. In long regimen group, there were three factors: $\mathrm{Tb}$ history ( $\mathrm{p}=0.05)$, HIV status (limit with $\mathrm{p}=0.06$ ), radiologic lesions extent ( $\mathrm{p}=$ 0.05). Multivariate analysis is summarized in Table 2 and Table 3. In the shot regimen group, 4 factors are shown: male sex, TB history, HIV status, and delay in treatment start. In the long regimen group, age and delay for treatment start are noted.

\section{Adverse events.}

In the group on long regimen, 53 (42.4\%) patients reported at least on drug adverse events. This was in 513 cases $(47.0 \%)$ in short regimen. Severe adverse events grade 3 - 4 were reported by $9(8.02 \%)$ patients in long regimen and 93 (9.8\%) patients in short regimen $(\mathrm{p}=0.350)$. Finds are detailed in Table 4. Most of the effects reported were mild or moderate except a few cases of hearing loss, severe anemia, psychiatric disturbances and skin allergy which remain less frequent. One case of hepatitis was documented in short regimen group. Hearing loss and vestibular disorders remain the important problem to solve in the two groups.

\section{Discussion}

Starting the new approach, the main challenge was to improve favorable outcomes in MDR/RR TB treatment in Kinshasa. It seemed urgent to extend patient-centered care policy [33]-[39]. All the health centers selected began with a training of health workers and community members [18] [36]. The short regimen used is the same as for the nine African Countries French speaker study [22]. It is different from those used in Bangladesh [25] [26], Niger [24] and Cameroon [23] where gatifloxacin took place of moxifloxacin. This short regimen is also different from that of the STREAM study [21] where Moxifloxacin was given in high dose. However, all the short regimen concerned reached high favorable outcomes rate between $78 \%$ and $88 \%$. In our study, favorable outcomes were about $81.9 \%$ in the short regimen and $72 \%$ in the long. These results were superior to those previously reported in Kinshasa [20]. Short regimen and new approach can explain it. [36]. 
Table 2. Characteristics of MDR-TB patients associated with unfavorable treatment outcomes in short regimen treatment group.

\begin{tabular}{|c|c|c|c|c|c|c|c|}
\hline \multicolumn{8}{|c|}{ Unfavorable outcome } \\
\hline & Characteristics & $\mathrm{n}$ & $\mathrm{n}(\%)$ & OR $(95 \% \mathrm{CI})$ & $P$ value & aOR (95\% CI) & $P$ value \\
\hline \multicolumn{8}{|c|}{ - Sex } \\
\hline & Female & 354 & $59(6.22)$ & Reference & - & Reference & - \\
\hline & Male & 534 & $113(11.9)$ & $1.17(0.83-1.66)$ & 0.363 & $1.54(0.99-2.39)$ & 0.055 \\
\hline \multicolumn{8}{|c|}{ - $\quad$ Age (years) } \\
\hline & $<25$ & 274 & $42(4.4)$ & Reference & - & Reference & - \\
\hline & $25-44$ & 488 & $97(10.2)$ & $1.37(0.92-2.03)$ & 0.12 & $1.04(0.65-1.66)$ & 0.862 \\
\hline & $\geq 45$ & 185 & $33(3.5)$ & $1.19(0.72-1.96)$ & 0.49 & $0.67(0.35-1.26)$ & 0.211 \\
\hline \multicolumn{8}{|c|}{ - BMI } \\
\hline & $<18.5$ & 370 & $52(5.5)$ & Reference & - & Reference & - \\
\hline & $18.5-24.9$ & 551 & $117(12.3)$ & $1.65(1.15-2.36)$ & 0.06 & $1.48(0.95-2.30)$ & 0.084 \\
\hline & $\geq 25$ & 27 & $3(0.3)$ & & & & \\
\hline \multicolumn{8}{|c|}{ - $\quad$ TB history } \\
\hline & No & 449 & $108(11.4)$ & Reference & - & Reference & \\
\hline & Yes & 499 & $64(6.7)$ & $0.46(0.33-0.65)$ & 0.000 & $0.58(0.39-0.88)$ & 0.01 \\
\hline \multicolumn{8}{|c|}{ - VIH Status } \\
\hline & Negative & 830 & $130(13.7)$ & Reference & - & Reference & - \\
\hline & Positive & 118 & $42(4.4)$ & $2.42(1.94-4.51)$ & 0.000 & $2.02(1.70-5.00)$ & 0.000 \\
\hline \multicolumn{8}{|c|}{ - Delay } \\
\hline & $<7$ & 101 & $32(3.4)$ & Reference & - & Reference & \\
\hline & $7-30$ & 588 & $81(8.5)$ & $0.34(0.21-0.57)$ & 0.000 & $0.49(0.27-0.89)$ & 0.02 \\
\hline & $>30$ & 259 & $34(5.6)$ & $0.64(0.38-1.05)$ & 0.082 & $0.98(0.52-1.85)$ & 0.951 \\
\hline \multicolumn{8}{|c|}{ - Lesions extent } \\
\hline & $<50 \%$ & 941 & $170(17.9)$ & Reference & - & Reference & \\
\hline & $\geq 50 \%$ & 7 & $2(0.2)$ & $1.81(0.35-9.43)$ & 0.479 & $2.51(0.38-16.61)$ & 0.341 \\
\hline \multicolumn{8}{|c|}{$\begin{array}{l}\text { Adverse Events } \\
(3-4)\end{array}$} \\
\hline & No & 855 & $162(17.1)$ & Reference & - & Reference & - \\
\hline & Yes & 93 & $10(1.6)$ & $0.52(0.26-1.02)$ & 0.055 & $0.63(0.29-1.37)$ & 0.243 \\
\hline
\end{tabular}

$\mathrm{MDR}-\mathrm{TB}=$ multidrug resistant tuberculosis, $\mathrm{OR}=$ odd Ratio, $\mathrm{CI}=$ confidence interval, $\mathrm{aOR}=$ adjusted odd ratio

Table 3. Characteristics of MDR-TB patients associated with unfavorable treatment outcomes in long regimen treatment group.

\begin{tabular}{ccccccc}
\hline \multicolumn{7}{c}{ Unfavorable outcome } \\
\hline Characteristics & $\mathrm{n}$ & $\mathrm{n}(\%)$ & OR $(95 \% \mathrm{CI})$ & P value & aOR $(95 \% \mathrm{CI})$ & P value \\
\hline Sex & & & & & & \\
Female & 50 & $11(8.8)$ & Reference & - & Reference & - \\
Male & 75 & $24(19.2)$ & $1.67(0.73-3.81)$ & 0.225 & $1.93(0.49-7.52)$ & 0.344 \\
\hline
\end{tabular}




\section{Continued}

- $\quad$ Age (years)

$\begin{array}{ccccccc}<25 & 44 & 12(9.6) & \text { Reference } & - & \text { Reference } & - \\ 25-44 & 47 & 18(14.4) & 1.66(0.68-4.01) & 0.265 & 4.85(0.96-24.4) & 0.055 \\ \geq 45 & 34 & 5(4.0) & 1.19(0.72-1.96) & 0.188 & 0.38(0.059-2.459) & 0.31\end{array}$

- BMI

$\begin{array}{ccccccc}<18.5 & 77 & 21(16.8) & \text { Reference } & - & \text { Reference } & - \\ 18.5-24.9 & 42 & 12(9.6) & 1.067(0.46-2.45) & 0.88 & 0.79(0.20-3.03) & 0.729 \\ \geq 25 & 6 & 2(4.8) & 1.33(0.23-7.82) & 0.75 & 0.096(0.58-2.47) & 0.248\end{array}$

- TB history

\begin{tabular}{|c|c|c|c|c|c|}
\hline No & 51 & $12(9.6)$ & Reference & - & Reference \\
\hline res & 74 & $23(18.4)$ & $1.47(0.65-3.30)$ & 0.02 & $3.33(0.778-14.26)$ \\
\hline
\end{tabular}

- HIV Status

$\begin{array}{lcccccc}\text { Negative } & 102 & 27(21.6) & \text { Reference } & - & \text { Reference } & - \\ \text { Positive } & 23 & 8(6.4) & 1.48(0.56-3.89) & 0.42 & 46(0.085-2.49)) & 0.37\end{array}$

- Delay

$\begin{array}{ccccccc}<7 & 45 & 20(16.0) & \text { Reference } & - & \text { Reference } & \\ 7-30 & 52 & 10(8.0) & 0.30(0.12-0.74) & 0.009 & 0.195(0.047-0.78) & 0.021 \\ >30 & 28 & 9(7.2) & 0.27(0.087-0.873) & 0.024 & 0.087(0.014-0.56) & 0.010\end{array}$

- Radiographic

Lesions extent

$\begin{array}{ccccccc}<50 \% & 123 & 34(27.2) & \text { Reference } & - & \text { Reference } \\ \geq 50 \% & 2 & 1(0.8) & 2.62(0.016-43.04) & 0.501 & 1.89(0.005-719.5) & 0.833\end{array}$

- Adverse Events

$(3-4)$

$\begin{array}{ccccccc}\text { No } & 116 & 34(27.2) & \text { Reference } & - & \text { Reference } & - \\ \text { Yes } & 3 & 1(0.8) & 0.30(0.036-2.50 & 0.267 & 0.49(0.03-7.97) & 0.616\end{array}$

MDR-TB $=$ multidrug resistant tuberculosis, $\mathrm{OR}=$ odd Ratio, $\mathrm{CI}=$ confidence interval, $\mathrm{aOR}=$ adjusted odd ratio.

Table 4. Adverse events.

\begin{tabular}{|c|c|c|c|}
\hline & Adverse events (AE) & $\begin{array}{c}\text { Régime court } \\
n=948\end{array}$ & $\begin{array}{l}\text { Régime long } \\
\mathrm{n}=125\end{array}$ \\
\hline & Cases with at least one $\mathrm{AE}$ & $513(63.9 \%)$ & $62(49.6 \%)$ \\
\hline & Grade 1 - $2(\mathrm{n}, \%)$ & $513(54.1 \%)$ & $53(42.4 \%)$ \\
\hline 0 & Gastro intestinal disorders & $307(31.9 \%)$ & $30(24.0 \%)$ \\
\hline 0 & Vertigo/dizziness & $86(9.1 \%)$ & $18(14.4 \%)$ \\
\hline 0 & Asthenia & $71(7.4 \%)$ & $10(8.0 \%)$ \\
\hline 0 & Arthralgia & $71(7.4 \%)$ & $3(2.4 \%)$ \\
\hline 0 & Anorexia & 67 (7.1\%) & $2(1.6 \%)$ \\
\hline
\end{tabular}




\section{Continued}

\begin{tabular}{|c|c|c|c|}
\hline 0 & Pruritus & $28(2.9 \%)$ & $4(3.2 \%)$ \\
\hline 0 & Psychiatric disturbance & $12(1.3 \%)$ & $6(4.8 \%)$ \\
\hline 0 & Peripheral neuropathy & $8(0.8 \%)$ & $8(6.4 \%)$ \\
\hline 0 & Mild anemia $(\mathrm{Hb} \geq 8 \mathrm{~g} / \mathrm{l})$ & $6(0.6 \%)$ & $4(3.2 \%)$ \\
\hline 0 & Facial paralysis & $1(0.6 \%)$ & 0 \\
\hline 0 & Sexual disturbance & $1(0.1 \%)$ & \\
\hline 0 & Grade 3 - $4(\mathrm{n}, \%)$ & $93(9.8 \%)$ & $9(7.2 \%)$ \\
\hline 0 & Severe hearing loss & $83(8.7 \%)$ & $2(1.7 \%)$ \\
\hline 0 & Retrobulbar neuritis & $11(1.1 \%)$ & $2(1.7 \%)$ \\
\hline 0 & Psychiatric troubles & $1(0.1 \%)$ & $2(1.6 \%)$ \\
\hline 0 & Severe anemia & $1(0.1 \%)$ & $3(2.4 \%)$ \\
\hline 0 & Hepatitis & $1(0.1 \%)$ & 0 \\
\hline 0 & Epidermolysis & $1(0.1 \%)$ & 0 \\
\hline
\end{tabular}

$(\mathrm{p}=0.350)$.

Delay observed to start the treatment is still long. This concerned about the third of patients mainly in the short regimen group where corner drugs were not supported by the Global Fund. It can influence the prognosis [40].

Culture conversion by 2 months was $87.5 \%$ and $83.6 \%$ respectively for short and long regimen. The profile of the 2 regimen showed little difference. This was also reported in other studies [21] [25] [26]. Two patients in the short regimen group and 3 in the long had the intensive phase extended. Between them, only one in the short regimen group was declared failure. The predictive role of culture conversion has been documented [41] [42] [43] [44].

Adverse events reported in this study are less than described in others [21] [22]. But they are similar to those encountered in Cameroon and Niger [23] [24]. This can be due to the system of self-declaration used. It belongs to patients to declare disorder observed and then underestimation can be possible especially for mild effects. A case of toxic hepatitis has been observed but it solved during treatment [21] [22] [26]. Hearing loss was the main adverse event in the two groups; it is reported in many studies [45] [46] [47] [48]. The answer will be possible with new drugs [49]-[56]. The death rate remains high. Most of cases were observed during the first two months. In bivariate analysis, a linkage appeared with sex male, HIV status, TB history, radiologic lesions extent and delay in treatment starting mainly in short regimen group. In multivariate analysis, sex, HIV status, previous TB history and delay in treatment starting expressed high significance in both group but mainly in the short regimen one. Risk factors for unfavorable treatment outcomes among MDR/ TB have largely been discussed [44] [45] [57] [58] [59]. Short regimen seems superior to long in term of death rate and LTFU even if the ECG regular follow up will be useful [60] [61] [62]. The patient-centered care policy is strongly indicated in low income coun- 
tries. Nutritional support remains essential to enhance adherence.

The death rate remains high. Most of the cases were observed on the onset of the treatment. The risk factors discussed above have been reported in other studies [55] [56] [58].

In this study, there was not QTc interval pathologic change. It was reported as rare by others [59] [60]. Regular ECG control is recommended during treatment [60] [61] [62].

\section{Limitations}

The limitations of this study are mainly related to its retrospective nature and the lack of randomization. The bacteriological follow-up was difficult as cultures are not easy to perform in a low income environment. So a lot of patients have been excluded.

\section{Conclusion}

The new approach improved favorable outcomes. Both short and long regimens reached a high level of favorable outcome compared to the previous study conducted in Kinshasa. The short regimen, well supervised seems to be superior to long regimen in term of Death rate and LTFU. The patient-centered care policy is indicated in low income country. Nutritional support and other measures remain essential to enhance adherence.

\section{Conflicts of Interest}

The authors declare that they do not have any financial interests pertaining to the information contained in this paper.

\section{References}

[1] Falzon, D., Mirzayev, F., Wares, F., et al. (2015) Multidrug-Resistant Tuberculosis around the World: What Progress Has Been Made? European Respiratory Journal, 45, 150-160. https://doi.org/10.1183/09031936.00101814

[2] Zager, E.M. and McNemey, R. (2008) Multidrug-Resistant Tuberculosis. BMC Infectious Diseases, 8, 10. https://doi.org/10.1186/1471-2334-8-10

[3] Uplekar, M., Weil, D., Lonnroth, K., et al. (2015) WHO’S New End TB Strategy. The Lancet, 385, 1799-1801. https://doi.org/10.1016/S0140-6736(15)60570-0

[4] World Health Organization (2016) WHO Treatment Guideline for Drug Resistant Tuberculosis. WHO.

[5] World Health Organization (2018) WHO Treatment Guidelines for Multidrug and Rifampicin-Resistant Tuberculosis, 2018 Update. World Health Organization, Geneva.

[6] Slown, D.J. and Lewis, J.M. (2016) Management of Multidrug-Resistant TB: Novel Treatments and Their Expansion to Low Resource Settings. Transactions of the Royal Society of Tropical Medicine and Hygiene, 110, 163-172. https://doi.org/10.1093/trstmh/trv107

[7] Migliori, G.B., D’Arcy Richardson, M., Sotgiu, G. and Lange, C. (2009) Multidrug-Resistant and Extensively Drug-Resistant Tuberculosis in the West Europe 
and United States: Epidemiology, Surveillance and Control. Clinics in Chest Medicine, 30, 637-665. https://doi.org/10.1016/j.ccm.2009.08.015

[8] Schaaf, H.S., Mall, A.P. and Dheda, K. (2009) Multidrug and Extensively Drug-Resistant Tuberculosis in Africa and South-America: Epidemiology, Diagnosis and Management in Adult and Children. Clinics in Chest Medicine, 30, 667-683.

https://doi.org/10.1016/j.ccm.2009.08.019

[9] Aznar, M.L., Rando-Segura, A., Moreno, M.M., et al. (2019) Prevalence and Risk of Multidrug-Resistant Tuberculosis in Cuba, Angola: A Prospective Cohort Study. International Journal of Tuberculosis and Lung Disease, 23, 67-72. https://doi.org/10.5588/ijtld.18.0231

[10] Seung, K.J., Keshavjee, S. and Rich, M.L. (2015) Multidrug-Resistant Tuberculosis and Extensively Drug-Resistant Tuberculosis. Cold Spring Harbor Perspectives in Medicine, 5, a017863. https://doi.org/10.1101/cshperspect.a017863

[11] Chen, M.P., Miramontes, R. and Kammerer, J.S. (2020) Multidrug-Resistant Tuberculosis in the United States 2011-2016: Patients Characteristics and Risk Factors. International Journal of Tuberculosis and Lung Disease, 24, 92-99. https://doi.org/10.5588/ijtld.19.0173

[12] World Health Organization (2015) Introduction of Bedaquiline for the Treatment of Multidrug-Resistant Tuberculosis at Country Level. Implementation Plan. Geneva. https://www.who.int/tb/publications/Bedaquiline-implementation-plan/en/

[13] World Health Organization (2014) Companion Handbook to the WHO Guidelines for the Programmatic Management of Drug Resistant Tuberculosis. Geneva.

[14] Gler, M.T., Skripconoka, V., Sanchez-Gravito, E., et al. (2012) Delamanid for Multidrug-Resistant Pulmonary Tuberculosis. The New England Journal of Medicine, 366, 2151-2160. https://doi.org/10.1056/NEJMoa1112433

[15] Reuter, A., Tisile, P., von Delft, D., Cox, H., Cox, V., et al. (2017) The Devil We Know: Is the Use of Injectable Agents for the Treatment of MDR-TB Justified? International Journal of Tuberculosis and Lung Disease, 21, 1114-1126. https://doi.org/10.5588/ijtld.17.0468

[16] Seddon, J.A., Godfrey-Faussett, P., Jacobs, K., et al. (2012) Hearing Loss in Patients on Treatment for Drug-Resistant Tuberculosis. European Respiratory Journal, 40, 1277-1286. https://doi.org/10.1183/09031936.00044812

[17] Pontali, E., D’Ambrosio, L., Ceutis, R., Sotgiu, G. and Migliori, G.B. (2017) Multidrug-Resistant Tuberculose and Beyond: An Updated Analysis of the Current Evidence on Bedaquiline. European Respiratory Journal, 49, Article ID: 1700146. https://doi.org/10.1183/13993003.00146-2017

[18] Cox, H., Reuter, A., Furin, J. and Seddon, J. (2017) Prevention of Hearing Loss in Patients with Multidrug-Resistant Tuberculosis. The Lancet, 390, 934. https://doi.org/10.1016/S0140-6736(17)32170-0

[19] Shringarpure, K.S., Isaakidis, P., Sagili, K.D., Baxi, R.K., Das, M. and Daftary, A. (2016) "When Treatment Is More Challenging than the Disease": A Qualitative Study of MDR-TB Patient Retention. PLoS ONE, 11, e0150849. https://doi.org/10.1371/journal.pone.0150849

[20] Murhula, I.K., Mawete, F., Ofali, L., Kaswa, M., Bompeka, F.L., Ntumba, J.M.K. and Munogolo, Z.K. (2019) Low Detection Rate of Multidrug-Resistant and Rifampicin-Resistant Tuberculosis in the Democratic Republic of Congo: Trend Analysis 2013-2017. Journal of Tuberculosis Research, 7, 212-219. https://doi.org/10.4236/jtr.2019.74020

[21] Nunn, A.J., Phillips, P.P.J., Meredith, S.K., Chiang, C.-Y., Conradie, F., Dalai, D., 
Van Deun, A., Dat, P.-T., Lan, N., Master, I., et al. (2019) A Trial of a Shorter Regimen for Rifampin-Resistant Tuberculosis. https://doi.org/10.1056/NEJMoa1811867

[22] Trébucq, A., Schwoebel, V. and Kashongwe, Z. (2018) Treatment Outcome with a Short Multidrug-Resistant Tuberculosis Regimen in Nine African Countries. International Journal of Tuberculosis and Lung Disease, 22, 17-25. https://doi.org/10.5588/ijtld.17.0498

[23] Kuaban, C., Noeske, J., Rieder, H.L., Aït-Khaled, N., Abena Foe, J.L. and Trébucq, A. (2015) High Effectiveness of a 12-Month Regimen for MDR-TB Patients in Cameroon. International Journal of Tuberculosis and Lung Disease, 19, 517-524. https://doi.org/10.5588/ijtld.14.0535

[24] Harouna, S.H., Ortuno Gutierrez, N., Souleymane, M.B., et al. (2019) Short Course Treatment Outcome and Adverse Events in Adults and Children Adolescents with MDR TB in Niger. International Journal of Tuberculosis and Lung Disease, 23, 625-630. https://doi.org/10.5588/ijtld.17.0871

[25] Van Deum, A., Aung, K.J.M., Halim, M.A., et al. (2010) Short, Highly Effective and Inexpensive Standardized Treatment of Multidrug-Resistant Tuberculosis. American Journal of Respiratory and Critical Care Medicine, 182, 684-692. https://doi.org/10.1164/rccm.201001-0077OC

[26] Aung, K.J.M., Van Deun, A., Declercq, E., et al. (2014) Successful “9-Month Bangladesh Regimen” for Multidrug-Resistant Tuberculosis among over 500 Consecutive Patients. International Journal of Tuberculosis and Lung Disease, 18, 1180-1187. https://doi.org/10.5588/ijtld.14.0100

[27] Trébucq, A., Decroo, T., Van Deun, A., Piubello, A., Chiang, C.Y., Koura, K.G. and Schwoebel, V. (2019) Short-Course Regimen for Multidrug-Resistant Tuberculosis: A Decade of Evidence. Journal of Clinical Medicine, 9, pii: E55. https://doi.org/10.3390/jcm9010055

[28] Paul, R. (2018) The Threat of Multidrug-Resistant Tuberculosis. Journal of Global Infectious Diseases, 10, 119-120. https://doi.org/10.4103/jgid.jgid 12517

[29] Agence Publique Française de Recherche sur le Sida et les Hepatites Virales (2003) Echelle ANRS de Cotation de la Gravité des Evénements Indésirables Chez l'adulte. Version 6, 9 Septembre 2003. ANRS, Paris.

[30] Nunn, A.J., Philips, P.P.J. and Mitchison, D.A. (2010) Timing of Relapse in Short-Course Chemotherapy Trials for Tuberculosis. International Journal of Tuberculosis and Lung Disease, 14, 241-242.

[31] Schwoebel, V., Chiang, C.Y., Trébucq, A., et al. (2019) Outcome Definitions for Multidrug-Resistant Tuberculosis Treated with Shorter Treatment Regimens. International Journal of Tuberculosis and Lung Disease, 23, 619-624. https://doi.org/10.5588/ijtld.18.0798

[32] Schwoebel, V., Trébucq, A., Kashongwe, Z., et al. (2020) Outcomes of Nine-Month Regimen for Rifampicin-Resistant Tuberculosis Up to 24 Months after Treatment Completion in Nine African Countries. E Clinical Medicine. https://doi.org/10.1016/j.eclinm.2020.100268

[33] Stender, S.C. and Christense, A. (2013) Patient-Centered Primary Health-Care Synergy Potential for Health Systems Strengthening. International Journal of Tuberculosis and Lung Disease, 17, S15-S21. https://doi.org/10.5588/ijtld.13.0356

[34] Tadesse, Y., Yesuf, M. and Williams, V. (2013) Evaluating the Output of Transformational Patient-Centered Nurse Training in Ethiopia. International Journal of Tuberculosis and Lung Disease, 17, S9-S14. https://doi.org/10.5588/ijtld.13.0386

[35] Tudor, C., Mphahlele, Vander Walt, M. and Farley, J.E. (2013) Health-Care Work- 
ers Fears Associated with Multidrug and Extensively Resistant Tuberculosis Words in South Africa. International Journal of Tuberculosis and Lung Disease, 17, S22-S29. https://doi.org/10.5588/ijtld.13.0109

[36] Hadley, M. and Maher, D. (2000) Community Involvement in Tuberculosis Control: Lessons from Other Health Care Programmes. International Journal of Tuberculosis and Lung Disease, 4, 401-408.

[37] Kwak, N., Kim, H.R., Yoo, C.G., et al. (2015) Changes in Treatment Outcomes of Multidrug-Resistant Tuberculosis, International Journal of Tuberculosis and Lung Disease, 19, 525-530. https://doi.org/10.5588/ijtld.14.0739

[38] Liefooghe, R., Suetens, C., Meulemans, H., et al. (1999) A Randomized Trial of the Impact of Counseling on Treatment Adherence of Tuberculosis Patients in Sialkot, Pakistan. International Journal of Tuberculosis and Lung Disease, 3, 1073-1080.

[39] Njoroge, A., Cassidy, S. and Williams, V. (2013) Making Patient Centered Care a Reality in the Slums of Entera Nairobi. International Journal of Tuberculosis and Lung Disease, 10, s5-s8. https://doi.org/10.5588/ijtld.13.0186

[40] Sherman, L.F., Fujiwara, P.I., Cook, S.V., et al. (1999) Patient and Health Care System Delays in the Diagnosis and Treatment of Tuberculosis. International Journal of Tuberculosis and Lung Disease, 3, 1088-1095.

[41] Bastard, M., Sanchez Padilla, E., Hayrapetyan, A., et al. (2019) What Is the Best Culture Conversion Prognostic Marker for Patients Treated for Mdrtb? International Journal of Tuberculosis and Lung Disease, 23, 1060-1062. https://doi.org/10.5588/ijtld.18.0649

[42] Dominguez-Castellano, A., Muniain, M.A., Rodriguez-Bano, J., et al. (2003) Factors Associated with Time to Sputum Conversion in Active Pulmonary Tuberculosis. International Journal of Tuberculosis and Lung Disease, 7, 432-438.

[43] Zhao, F.Z., Levy, M.H. and Wen, S. (1997) Sputum Microscopy Results at Two of Tuberculosis Treatment. International Journal of Tuberculosis and Lung Disease, 1 , 570-572.

[44] Nair, D., Velayutham, B., Kannan, T., Tripathy, J.P., et al. (2017) Predictors of Unfavourable Treatment Outcome in Patients with Multidrug-Resistant Tuberculosis in India. Public Health Action, 7, 32-38. https://doi.org/10.5588/pha.16.0055

[45] Kibret, K.T., Moges, Y., Memiah, R., et al. (2017) Treatment Outcomes for Multidrug-Resistant Tuberculosis under DOT Is Plus: Analysis of Published Studies. Infectious Diseases of Poverty, 6, 7. https://doi.org/10.1186/s40249-016-0214-X

[46] World Health Organisation (2019) WHO Consolidate Guidelines on Drug Resistant Tuberculosis. WHO, Geneva.

[47] Hong, H., Dowdy, D.W., Dooley, K.E., Francis, H.W., et al. (2020) Risk of Hearing Loss among Multidrug Resistant Tuberculosis Patients According to Cumulative Aminoglycoside Dose. International Journal of Tuberculosis and Lung Disease, 24, 65-72. https://doi.org/10.5588/ijtld.19.0062

[48] Ghafari, N., Rogers, C., Petersen, L. and Singh, S.A. (2015) The Occurrence of Auditory Dysfunction in Children with TB Receiving Ototoxic Medication at a TB Hospital in South Africa. International Journal of Pediatric Otorhinolaryngology, 79, 1101-1105. https://doi.org/10.1016/j.ijporl.2015.04.040

[49] Seung, K.J., Omatayo, D.B., Keshavjee, S., Furin, J.J., Farmer, P.E., et al. (2009) Early Outcomes of MDR-TB Treatment in a High HIV-Prevalence Setting in Southern Africa. PLoS ONE, 4, e7186. https://doi.org/10.1371/journal.pone.0007186

[50] Pym, A.S., Diacon, A.H., Tang, S.J., et al. (2016) Bedaquiline in the Treatment of Multidrug and Extensively Drug Resistant Tuberculosis. European Respiratory 
Journal, 47, 564-574. https://doi.org/10.1183/13993003.00724-2015

[51] Zhao, Y., Fox, T., Manning, K., et al. (2019) Improved Treatment Outcomes with Bedaquiline When Substituted for Second Line Injectable Agents in Multidrug Resistant Tuberculosis: A Retrospective Cohort Study. Clinical Infectious Diseases, 68, 1522-1529. https://doi.org/10.1093/cid/ciy727

[52] Guglielmetti, L., Hewison, C., Avaliani, Z., et al. (2017) Examples of Bedaquiline Introduction for the Management of Multidrug-Resistant Tuberculosis in Five Countries. International Journal of Tuberculosis and Lung Disease, 21, 167-174. https://doi.org/10.5588/ijtld.16.0493

[53] Guglielmetti, L., Le Dû, D., Jachym, M., et al. (2015) Compassionate Use of Bedaquiline for the Treatement of Multidrug-Resistant and Extensively Drug Resistant Tuberculosis: Interim Analysis of French Cohort. Clinical Infectious Diseases, 60, 188-194.

[54] Cox, V., Brigden, G., Crespo, R.H., et al. (2018) Global Programmatic Use of Bedaquiline and Delamanid for the Treatment of Multidrug-Resistant Tuberculosis. International Journal of Tuberculosis and Lung Disease, 22, 407-412. https://doi.org/10.5588/ijtld.17.0706

[55] Schnipel, K., Ndjeka, N., Maartens, G., et al. (2018) Effect of Bedaquiline in South African Patients with Drug-Resistant Tuberculosis: A Retrospective Cohort Study. The Lancet Respiratory Medicine, 6, 699-706. http://www.thelancet.com/respiratory https://doi.org/10.1016/S2213-2600(18)30235-2

[56] Ndjeka, N., Conradie, F., Schnippelk, et al. (2015) Treatment of Drug Resistant Tuberculosis with Bedaquiline in High HIV Prevalancesetting: An Interim Cohort Analysis. International Journal of Tuberculosis and Lung Disease, 19, 979-985. https://doi.org/10.5588/ijtld.14.0944

[57] Harousz, C.H., Rich, M., et al. (2015) QTc Prolongation and Treatment of Multidrug-Resistant Tuberculosis. International Journal of Tuberculosis and Lung Disease, 19, 385-391. https://doi.org/10.5588/ijtld.14.0335

[58] Conally, C., Dovies, G.R. and Wilkinson, D. (1999) Who Fails to Complete Tuberculosis Treatment; Temporal Trends and Risk Factors for Treatment Interruption in a Community-Based Directly Observed Therapy Program in a Rural District of South Africa. International Journal of Tuberculosis and Lung Disease, 3, 1081-1087.

[59] Gupta, N. and Jowal, P. (2018) Treatment Outcomes Associated with Multidrug-Resistant Tuberculosis. Journal of Global Infectious Diseases, 10, 125-128. https://doi.org/10.4103/jgid.jgid 9617

[60] Lange, C., Aarnouste, R.E., Alffenar, J.W.C., et al. (2014) Management of Patients with Multidrug-Resistant Tuberculosis. International Journal of Tuberculosis and Lung Disease, 23, 645-662. https://doi.org/10.5588/ijtld.18.0622

[61] Sanchez-Montalva, A., et al. (2018) QTc and Antituberculosis Drugs: A Perfect Storm or Tempest in Teacup? Review of Evidence and Risk Assessment. International Journal of Tuberculosis and Lung Disease, 22, 1411-1421. https://doi.org/10.5588/ijtld.18.0423

[62] Makhmudova, M., Maxsumova, Z., Rajabzoda, Z., et al. (2019) Risk Factors for Unfavorable Treatment Outcomes among Rifampicin-Resistant Tuberculosis Patients in Tajikistan. International Journal of Tuberculosis and Lung Disease, 23, 331-336. https://doi.org/10.5588/ijtld.18.0311 